\title{
CORRIGENDUM
}

\section{Black reefs: iron-induced phase shifts on coral reefs}

Linda Wegley Kelly, Katie L Barott, Elizabeth Dinsdale, Alan M Friedlander, Bahador Nosrat, David Obura, Enric Sala, Stuart A Sandin, Jennifer E Smith, Mark JA Vermeij, Gareth J Williams, Dana Willner and Forest Rohwer

The ISME Journal (2012) 6, 708; doi:10.1038/ismej.2011.148

Correction to: The ISME Journal (2012) 6, 638-649; doi:10.1038/ismej.2011.114; published online 1 September 2011

Since the publication of this article, the authors have noticed an omission in the acknowledgements section:

This work was carried under a permit from the Palmyra Atoll National Wildlife Refuge, US Fish and Wildlife Service at the Department of the Interior.

This error has now been rectified, and the correct article appears in this issue. The html and online pdf versions have also been rectified, and now carry the correct paper.

The authors would like to apologise for any inconvenience caused. 